\title{
Discussion on the Reform of Community Nursing Practice Teaching
}

\author{
Xiangyan Feng ${ }^{1, a}$ and Xiaona Jin $^{2, b^{*}}$ \\ ${ }^{1}$ Xi'an peihua University, Xi'an, Shaanxi, China; Post:710125) \\ ${ }^{2}$ Xi'an International University, Xi'an, Shaanxi, China; Post:710077 \\ a24138388@qq.com, jinxiaonamv@163.com \\ * The corresponding author
}

Keywords: Nursing Students; Community Nursing; Practice Teaching; Effect Evaluation

\begin{abstract}
Purpose] Explore the practical teaching effects of community nursing and provide qualified personnel for the community. [Method] Taking 204 nursing students in 4 classes of Grade 2016 as the research object, there were 204 students, including 22 boys and 182 girls. Each class is randomly divided into 10 groups. Practical teaching programs include visits to community health service centers and interviews with real patients; visit simulations for special families; simulated health education, etc. Each group freely chooses the practical teaching program. [Result] 99\% students believe that "the study of this course is an invaluable experience". 94.1\% students think that the study of this course has broadened their thinking and made them able to draw inferences about other cases from one instance. In contrast, $99.5 \%$ nursing students think that it is well worth it taking the time and energy to participate in the study of the course. [Conclusion] The overall effect of practical teaching is good. It can stimulate students' interest in independent study, improve the ability to analyze and solve problems, and the ability to collaborate and communicate.
\end{abstract}

\section{Introduction}

Community nursing is a comprehensive discipline that combines nursing and public health theory to promote and maintain the health of community populations [1]. "The Outline of the "Healthy China 2030 Plan" mentions: Adjusting and optimizing the structure of the medical education profession that adapts to the development of the health service industry and intensifying the training of health personnel such as nursing care workers, rehabilitation therapists, and psychological counselors. Practice teaching is an important component of community nursing education and it is very important for the cultivation of students' abilities [2]. The contents of practical teaching not only involve disease care, but also include health promotion, health care, disease prevention, rehabilitation, and family planning guidance [3]. In the teaching of community nursing practice, designing a reasonable teaching practice project is an important part of practical teaching. This study is to create a meaningful learning environment for students that enables them to obtain real experiences to develop students' comprehensive application of professional knowledge and skills, ability to independently handle and resolve patient health problems, and good professional qualities. On the basis of the selection of practical teaching content, strive to make the teaching content highlight "applicability, practicality, professionalism, and feasibility", and combine closely with the position; According to the needs of the development of community health services, new knowledge and skills are constantly added. After the practical teaching is over, evaluate its effect.

\section{Objects and Methods}

Research Objects. 4 classes of nursing students at Grade 2016 are taken as the research objects. There are totally 204 students, including 22 boys and 182 girls. Inclusion criteria: The nursing care students of Grade 2016 of our school who are admitted through the college entrance examination voluntarily participate in the study. Exclusion criteria: Self-assessment of enrollment and reluctance to participate in this study. 


\section{Research Methods.}

Class assignment: Community nursing started in the fourth semester, with a total of 24 academic hours, including 20 hours of theory and 4 hours of practice. Establish a community nursing teaching plan. According to the theoretical teaching content of the community care plan, the community care coverage of the community care plan can be summarized into three modules of community care practice projects, including visits to the community health service center under the leadership of the community health service center and the real Interviews were conducted with patients; visit simulation exercises for special families (neonatal families, families with chronic diseases, home care, etc.); simulated health education for special populations, etc.

Practice teaching method: Each class was randomly divided into 10 groups of 4 to 5 people each. Freely choose practical teaching projects. During the whole process, students are taken as the main body, and through the preparation of practical projects, students' ability of literature review and active learning are cultivated. Through on-site interviews, it is helpful to cultivate students' language expression and communication skills; through simulation of health education, the ability to enhance their health education; In the form of a group, it is conducive to cultivating the sense of teamwork; all practical activities are conducive to the cultivation of professional emotions and community service awareness of nursing students. In order to ensure that each student can participate actively, each small component worker is clearly identified, indicating the work done by the members in completing the practical teaching project and the proportion of all jobs.

Effect Evaluation. After the course was completed, the students' self-employed questionnaire was used to investigate and give feedback on the students' learning. The survey questionnaire was distributed on the spot and collected on the spot, 204 questionnaires were distributed, 204 valid questionnaires were retrieved, and the effective recovery rate was $100 \%$. And 10 students were interviewed to understand their assessment of the curriculum. According to feedback from nursing students, we adjusted the design of practical teaching.

Statistical Method. All returned questionnaires were uniformly numbered and entered into the system for two persons. SPSS20.0 software was used for statistical analysis of the data.

\section{Results}

Nursing Students' Satisfaction with Teaching. Generally speaking, students are satisfied with the practical teaching and learning experience of the course, and most of their satisfaction is above $90 \%$. See Table 1.

Table 1 Survey on Nursing Students' Satisfaction with Community Practice Courses Example (\%)

\begin{tabular}{|l|l|l|l|l|}
\hline Item & $\begin{array}{l}\text { Rather } \\
\text { disagree }\end{array}$ & Disagree & Agree & Rather agree \\
\hline $\begin{array}{l}\text { 1. For me, the study of this course is an invaluable } \\
\text { experience }\end{array}$ & $0(0)$ & $2(1)$ & $95(46.6)$ & $107(52.4)$ \\
\hline $\begin{array}{l}\text { 2. The study of this course has led me to pay more attention } \\
\text { to my own feelings and reactions. }\end{array}$ & $0(0)$ & $7(3.4)$ & $67(32.9)$ & $130(63.3)$ \\
\hline $\begin{array}{l}\text { 3. I think it is worthwhile to spend time and energy to } \\
\text { participate in this course. }\end{array}$ & $0(0)$ & $1(0.5)$ & $93(45.6)$ & $110(53.9)$ \\
\hline $\begin{array}{l}\text { 4. The study of this course helped me gain important } \\
\text { community basic knowledge }\end{array}$ & $0(0)$ & $9(4.4)$ & $45(22.1)$ & $150(73.5)$ \\
\hline $\begin{array}{l}\text { 5. The study of this course allowed me to broaden my } \\
\text { thinking and made me draw more references about other } \\
\text { cases from one instance }\end{array}$ & $0(0)$ & $12(5.9)$ & $67(32.8)$ & $125(61.3)$ \\
\hline
\end{tabular}

Nursing Students' Feedback on Teaching. Interviews were conducted on 10 randomly selected subjects. The recommendations of nursing students' interviews focused more on "a little more practice, learning to apply theoretical knowledge"; Simulated health education wants to try real health education for real patients; teachers can provide more extracurricular materials or related learning resources. Some classmates also reported that they did not like random groupings and 
enjoyed the freedom of collocation. There were too many kinds of styles, and they took up more time after school and the burden was heavier.

\section{Discussion}

Improve Students' Autonomy and Interest in Learning. Nursing students realize the relevance of theoretical knowledge and clinical practice by truly experiencing the role of community nurses. In particular, personal contact with patients to perceive the needs and reactions of patients greatly stimulate students' interest in learning and clear motivations for learning. They truly improve their self-learning consciousness from theory to practice. [4] This is also consistent with the findings in Table 1 that $99 \%$ believe that the study of the course is a very valuable experience. Many nursing students mentioned in the reflection report that "there are many deficiencies in self-discovery and have gained a lot of experience", pointing out the future direction of learning for nursing students.

Students' effective participation is based on the theory of humanistic significance. From the perspectives of people's self-realization and personal meaning, they put forward their views on learning. They fully respect the students in their studies, pursue a learning environment that allows students to make personal choices, and pay attention to students' participation and experience in learning and training so that students find themselves autonomously, enhance the subjectivity of student learning [5]. Table 1 shows that $99.5 \%$ nursing students think it is worthwhile to spend time and energy to participate in this course.

Improves Students' Teamwork and Communication Skills. Nursing students conduct community practice in groups and have a clear division of labor among members. This effectively cultivates the teamwork abilities of nurse students and helps improve nursing students' critical thinking skills. Community nursing work not only needs the close cooperation of peers, but also needs multi-sector collaboration to ensure the smooth development of the work. Through practical activities, students' communication skills have been greatly improved.

Deepen Students' Understanding of Community Nursing Knowledge. Through a series of community nursing practice activities, nursing students can not only learn and understand the knowledge and life experience that are not available in community nursing textbooks, but also improve their community practice capabilities. They can also better understand the roles and functions of nurses and deeply understand the role and connotation of community nursing, establish a positive sense of responsibility, a sense of mission and professional attitude [6]. Secondly, by simulating the role of health education, nursing students can deeply analyze the needs of the role and experience the patient's inner feelings through empathy, which helps to cultivate the compassion, love and injury concepts and other intrinsic qualities of nursing students; The ability of nursing students to communicate and coordinate and manage is also strengthened and consolidated in their contact with "patients" and "patients' families". Moreover, this study also helps nursing students to reflect the patient's care needs according to their own experience background by reflecting the diary form of their practice writing experience. They can also perceive the experience and experience in the secondary school [7]. This study confirms that $95.6 \%$ nursing students think that "the study of this course has helped me acquire important basic knowledge of the community".

Improve Students' Health Education Ability. Health education is an important part of nursing work. The diversity of community health education practice is a good opportunity to cultivate students' theory and practice [8]. Table 1 shows that: $94.1 \%$ students think that the study of this course has opened my mind and can infer some ideas. Health education is one of the skills that must be possessed by nursing students. Many courses have organized students to conduct simulated lectures in teaching. However, to go to the community and conduct health education for different groups in the community, higher requirements are placed on students. From the design of health education, the production, presentation and interaction of slides require the students of the group to ensure accuracy, pertinence and practicality. Through the community health education simulation practice, students are familiarized with the process of community health education, integrate the knowledge they have learned, and guide community residents in some nursing techniques to improve their overall health education capabilities. 


\section{Conclusion}

The teaching reform of community nursing practice is characterized by nursing students as the main body of learning, targeting the core competences required in the professional context, designing practical teaching modules centering on work tasks, inspiring the interest of nursing students in independent learning, and improving the analysis and solving problems. The ability to communicate and communicate collaboratively reshapes the concept of humanistic care of nursing students and effectively promotes the comprehensive development of nursing students' knowledge, skills, emotions, attitudes, etc., thereby improving the competence of nursing students in community nursing work.[9] Integrate students into all aspects of teaching, highlight the main body of student learning, provide a good platform for training their practical ability, promote the combination of community nursing theory and practice, improve the quality of community nursing practice teaching, and improve the overall quality of students. Social and economic development requires the participation of practical talents with practical abilities. Colleges and universities should expand social service functions and combine the cultivation of applied talents with the realities of social and economic development [10]. Through the reform of community practice courses, we have tried to carry out activities such as family health services and health education lectures. Later, we will take simulated health education lectures and simulated family visits to real communities and face real residents. This will not only improve the students' comprehensive ability, but also solve existing and potential health problems of residents, popularize health knowledge, and achieve a win-win situation for colleges and communities.

\section{References}

[1] Xinfeng Jiang, Xiuqing Wang. Community Nursing [M]. Beijing: People's Medical Publishing House, 2016.

[2] Yujing Dong, Aihong Wang, Haiyan Yin. "Community Nursing" Practice Teaching Project Design and Effect Evaluation [J]. Nurse Training Magazine, 2016,31(07):626-628.

[3] Suzhen Liu, Hong Xie. Analysis on the Characteristics and Present Situation of Community Nursing Practice Teaching[J] . Chinese Journal of Practical Nursing, 2016, 22( 36) : 51-52.

[4] Fengqin Zhang, Hongyu Chen, Juan Ding, et al. The Influence of the "Three Early-Class Probation" Models on Vocational Nursing Students' Self-directed Learning Capability[J]. Nurse Training Journal, 2016, 31(9): 824-826.

[5] Qin Su. Research on Students' Participation in Blended Learning Environment[D]. Wuhan: Central China Normal University, 2015: 1.

[6] Qing Xiong, Xiaochun Liao. Discussion on Practice of Community Nursing Teaching in University Nursing Students[J] . Chinese Health Industry, 2013, 10(07):37.

[7] Chenchen Gao, Anli Jiang. Application of Narrative Education in Nursing Humane Care Education[J] . People's Liberation Army Nursing Journal, 2013, 30(11): 31-33.

[8] Lili Yang, Cuizhen Shen, Qin Shen, Ling Li. Influence of Students' Effective Participation on the Effect of Community Nursing Practice Teaching [J]. Nursing Research, 2018,32(02): 274-276.

[9] Yuxia Li, Liping Li. Competency-oriented Teaching Reform of Community Nursing Practice [J]. Nurse Training Magazine, 2017,32(08):712-715.

[10] Lin Tang, Rui Jin. Research on the Extension of University Social Service Functions from the Perspective of New Normal [J]. Journal of Hebei University of Engineering (Social Science Edition), 2016, 33 (1): 25-28. 